\title{
International Distance Consulting via Web Conferencing
}

\author{
http://dx.doi.org/10.3991/ijet.v9i4.3736 \\ Prachyanun Nilsook and Panita Wannapiroon \\ King Mongkut's University of Technology North Bangkok, Bangkok, Thailand
}

\begin{abstract}
The objective of this research is to study the result of the use of international distance consulting via web conferencing. The research discovered that: 1) the open source programs can only be used with desktop computers, and not with laptop computers 2) the result of the use throughout the consulting process is considered normal 3) there are some observations which are different to the criteria of evaluation: the picture quality, the sound quality, the interaction during the consulting and the file management of the system. The students agree with international distance consulting via a web conferencing process that consists of 5 steps: 1) Preparation of the consulting system 2) Problem survey 3) Problem study 4) Determination of the objective and resolution of the problem 5) Making evaluations of the consulting system.
\end{abstract}

Index Terms-International Distance Consulting, Web Conferencing, Open Meeting Program, Open Source Program.

\section{INTRODUCTION}

Distance conferencing via web or web conferencing is a conferencing system via the Internet that is different to wired videoconferencing in that the latter is more accurate and stable while the first has a lot of relevant factors that are necessary to study in detail to plan the proper installation for the organizations [1]. However, the distance conferencing system via optical fiber requires a high cost for the installation, both for the tools and the rental of coaxial cable. This system is suitable for the organization that needs to keep the conference confidential and without any interruption. On the other hand, the distance conferencing via web requires, especially, the quality of the internet connection [2]. The biggest advantage of the conferencing via web is that it is more economic and has a variety of systems to be used to reduce the costs to the organization [3]. In particular, the open source programs such as DimDim, that have been investigated and evaluated for development [4]. A well-known open source distance conferencing via web conferencing system is a web conferencing system called Open Meeting [5]. The Open Meeting program has been developed to be a specific program including the essential tools that are: video communication, sound communication, conference recording, window interchange, shared data modification, chat and whiteboard, users and conference room management [6]. The users can also use the microphone or webcam, exchange the data on whiteboard, modify and save changes in the data [7]. Furthermore, they can install the program on unlimited servers and can share with unlimited clients as well [8].

Web conferencing is very useful for education; the teachers can apply it as a distance classroom where the students can learn just like a traditional live classroom and have a real-time interaction with the teachers [9]. This is especially so in graduated education, in which the learners can use the whiteboard, post the questions, send the document files or can show a presentation with slides via web conferencing [10]. In addition, the students can use this system to create a group for investigation online instead of the face-to-face communication in the traditional classroom [11. Using this system, it is possible to make a relationship between students and students or students and teachers like they have in a traditional classroom, although it is a distance classroom [12]. Therefore, the students feel like they are a part of a classroom and do not feel embarrassed or unfamiliar [13].

The criteria to evaluate the quality of web conferencing in the commercial aspect consists of: distinguishing characteristics, sound quality, motion quality, bandwidth management, cost, stability, security, service support, ease of installation, ease of use, ease of management, and other technological characteristics [14]. Info-Tech Research Group [15] proposes the criteria to evaluate web conferencing in terms of: video quality, chat, web board, white board, user's participation, questions posting, picture and sound combination of the system, sound quality on the network, security, platform, instruction tools, service, and mobile usage. The evaluation criteria of the Web Junction group [16] are divided into 5 sections, which are: program overview, usage, participants of the conference, interaction and applied technology. Those criteria are applied to the business conferencing [17] while the Open Meeting program is an open source program and free. In consequence, this research applies the specific appropriate criteria that are: picture quality, sound quality, consulting interaction and file management of the system.

International distance consulting using information technology is frequently used in the cooperation between international universities. For example, the cooperation between the University of Adelaide and the Pennsylvania State University in an online consultation of 12 graduate Australian students and 10 American students via Facebook throughout the semester. In this case, Facebook became a strong network for the cooperation between the two universities [18]. The students' perception is that the social network is considered a learning center that helps them to have an interaction with the teachers [19]. Although research shows that social networks are always used as a chat room, they are used in the investigation and research process more than other uses [20]. Thus, the distance consulting satisfies both the adviser and the advisee.

In this research, our research team started the web conferencing from Edith Cowan University, Mount Lawley campus, Perth, Australia with the laptop computer in the 
ML 13.207 laboratory where the hi-speed internet for the university's staff has been installed (the average speed is $300 \mathrm{Mbps}$ ). Then we opened the web conferencing from the server at King Mongkut's University of Technology North Bangkok (KMUTNB), accessible at http://202.28.17.21:5080/openmeetings/. This is a distance consulting setup between the students in Thailand and in Australia, and at the same time, we have also started distance consulting with the Ph.D. students who are investigating in Sacramento, California, USA. So, this is also considered the international distance consulting between Australia and USA in order to study the result of the use of the open source program via the server in Thailand that will be a guideline for the future distance conferencing between universities.

\section{Methodology}

\section{A. Research Objectives}

To study the result of the use of web conferencing for international distance consulting via the server at King Mongkut's University of Technology North Bangkok.

To study the process of international distance consulting via web conferencing in order to enhance the efficiency of investigation of graduate students.

\section{B. Research Scope}

This research includes the study of the result of the use of web conferencing for international distance consulting via the server at King Mongkut's University of Technology North Bangkok in two modes that are 1) distance consulting between Thailand and Australia and 2) distance consulting between Australia and the USA using the web conferencing system via the Open Meeting program as a investigation tool. The population of this research is 5 Ph.D. students who participated in the distance consulting for consultation about the ideas for their theses. In this group, the 4 students live in Thailand and another one lives in USA.

First of all, the research team has tested the international distance consulting system with the most popular browsers: Internet Explorer, Mozilla Firefox, Google Chrome and Safari that is an application for the iOS2 operation in Apple smartphones and tablets. To test the basic function of the system, the research team has opened those browsers both in Thailand and in Australia.

The team has tested those browsers (Internet Explorer, Mozilla Firefox, Google Chrome and Safari) on the laptop computer that is used for this research by opening them in the same computer at http://202.28.17.21 and we can normally access the webpage. Once we need to go to the portal webpage of the distance conference, we can login with our usernames and passwords without any problem and then we can use the whiteboard, webcam, microphone and other tools for the conference as well.

Second, the research team then takes another browser test for the distance consulting via web conferencing using the smartphone iphone $4 \mathrm{~s}$ with the browser Safari. We accessed the portal webpage of the distance conference at http://202.28.17.21 and we can normally access the webpage. But once we clicked to access the conferencing area, the system showed the text 'Cannot Open Page; Safari could not open the page because the server stopped responding', that means we cannot open the web conference since the server in Thailand does not respond.
The last test is for the distance consulting via web conferencing using the ipad 2 tablet with the browser 'Safari'. We can access the portal webpage of the distance conference at http://202.28.17.21 and we can normally go to the webpage. But once we clicked to access to the conferencing area, the system showed the text 'Cannot Open Page; Safari could not open the page because the server stopped responding', that means we cannot open the web conference like in the second test since the server in Thailand does not respond either.

Therefore, the research team decided to use the browser installed only in the computers. The test shows that the browsers installed on Windows operating system have the same result of the use of the Open Meeting program.

\section{Research Method}

In this research we use mixed methods including observation, interview and participation in distance consulting. The process of installation and system management is performed by the research team in 2 modes.

The first mode is the international distance consulting via web conferencing between Thailand and Australia. In this mode the researcher is in the laboratory in Australia and the 4 research participants who are the Ph.D. students, in the classroom at the Graduate School of King Mongkut's University of Technology North Bangkok. The theme of the consulting is related to the title of $\mathrm{Ph}$.D. theses of the Information and Communication Technology for Education program, Faculty of Technical Education. The schedule of the consulting is 2 hours per person in 2 days, from 9.00-12.00 am. During this consulting process we have 2 researchers in Australia and a consultant committee in Thailand. In addition, there is another researcher who controls the consulting process and resolves the problems that could occur during the consulting process.

The second mode is the international distance consulting via web conferencing between Australia and USA performed by a researcher in the laboratory in Australia and a Ph.D. student who is a research participant and is in Sacramento, USA. Using the observation and interview methods, the research found that the conversation via distance conferencing system using the server in Thailand has a good quality of picture and sound. The participants can write text and erase them on the whiteboard quickly and efficiently and they can also upload picture and document files quickly.

The process of the international distance consulting via web conferencing for the graduate students starts by planning the international distance consulting using web conferencing system as a communication channel between the advisor and the advisee. The process of the distance consulting is divided into 5 steps consisting of:

- Preparation of the consulting system by preparing the communication tools, computers and smartphones; the connection of the network of each program and making a schedule of the consulting as follows:

- Problem survey. The most common problems for the graduate students are the scope and the process of research, and the order of research themes.

- Understanding the problem to provide consultation quickly and efficiently. In this case, the students can send the relevant documents to the advisor via social networks in advance and then they can make an appointment with the advisor. 


\section{SHORT PAPER \\ INTERnATIONAL Distance CONSUlting VIA WEB CONFERENCING}

- Determine the objective and resolve the problems, providing the suggestions and correcting the points that are problems or questions asked by the students. Then the advisor could indicate the duration, assignments, and objectives for the students to modify their theses and to send them back for revision again.

- Make evaluations of the consulting system considering the result of the student's thesis and the progression of the thesis and the resolved problems, evaluating the students' potential of research performing and taking a research progression examination.

The next process includes: performing the international distance consulting via social networks and mobile applications to improve the graduate student's potential to do the research, continually making the appointment for the distance consulting, checking the student's research following the determined schedule, sending the suggestions through the social networks and making an appointment for the consultation via mobile applications, evaluating the student's potential to do the research with observation, interview, participation in distance conferencing, evaluating students' theses, evaluating participation satisfaction by asking about opinions and taking questionnaires via social networks.

\section{RESULT}

The research team has studied the result of the use of web conferencing for international distance consulting and the conclusion is as follows:

Web conferencing is an open source program that can only function with the browsers installed on desktop computers, but not with laptop computers. The web conferencing system for international distance consulting can be used normally throughout the process, but we found some differences between the use of web conferencing for distance consulting between Australia and Thailand, and the use of web conferencing for distance consulting between Australia and USA in the aspects of picture, sound, consulting interaction and files management of the system.

TABLE I.

THE DIFFERENCES FOUND IN THE INTERNATIONAL DISTANCE CONSULTING

\begin{tabular}{|l|l|l|}
\hline Differences & \multicolumn{1}{|c|}{ Australia-Thailand } & \multicolumn{1}{c|}{ Australia-USA } \\
\hline Picture & $\begin{array}{l}\text { The picture signal is clear } \\
\text { and has a good definition, } \\
\text { although it is not as high a } \\
\text { level as the system of } \\
\text { Skype or Facebook }\end{array}$ & $\begin{array}{l}\text { The picture signal is not clear } \\
\text { comparing with the system } \\
\text { of Skype or Facebook. There } \\
\text { is a juddering. }\end{array}$ \\
\hline Sound & $\begin{array}{l}\text { On the Thailand side, the } \\
\text { sound is low and not clear, } \\
\text { while in the Australia side, } \\
\text { the sound is clear. Alt- } \\
\text { hough we switched to } \\
\text { using the laptop computer } \\
\text { and then the microphone, } \\
\text { the result is the same. }\end{array}$ & $\begin{array}{l}\text { On the USA side, the sound } \\
\text { is as clear as on the Australia } \\
\text { side, but it is a little slow to } \\
\text { hear the sound on another } \\
\text { side. } \\
\text { There is sound echo and } \\
\text { delay. We cannot turn up the } \\
\text { sound a lot since this will } \\
\text { cause a 'howling sound' with } \\
\text { the microphone. }\end{array}$ \\
\hline $\begin{array}{l}\text { Consulting } \\
\text { interaction }\end{array}$ & $\begin{array}{l}\text { Once the participant clicks } \\
\text { on a tool, for example text } \\
\text { tool, there is a problem } \\
\text { with the font. The graphic } \\
\text { display is slow and to } \\
\text { move the objects, we have } \\
\text { to wait. }\end{array}$ & $\begin{array}{l}\text { The text tool can function } \\
\text { quickly and the graphic } \\
\text { displays such as the cursor } \\
\text { can also move quickly. The } \\
\text { screen clearance or the object } \\
\text { movement can be quickly } \\
\text { performed. }\end{array}$ \\
\hline $\begin{array}{l}\text { Files man- } \\
\text { agement of } \\
\text { the system }\end{array}$ & $\begin{array}{l}\text { Files uploading and dis- } \\
\text { play is quite slow. }\end{array}$ & $\begin{array}{l}\text { Files uploading and display } \\
\text { is fast. }\end{array}$ \\
\hline
\end{tabular}

The students agree with the international distance consulting via web conferencing process that consists of 5 steps: 1) Preparation of the consulting system 2) Problem survey 3) Problem study 4) Determination of the objective and resolution of the problem 5) Making evaluations of the consulting system. The students who have participated in this distance consulting have a high level of satisfaction.

\section{Discussion}

The result of this research shows that the web conferencing that is an open source program cannot be used with the browser of Apple's operation. This is a problem to be studied and resolved in the future investigation for developing because the web conferencing used in commercial system can function with all the browsers [21] and can be used for the world-wide communication [22]. The communication via web conferencing is considered as consulting in real time, so the picture and sound quality should be quite good. But the consulting between Australia and USA has a delay signal because of the delay of time while the consulting between Thailand and Australia has no problems of the level of speed of communication. This problem may occur because of the distance between Australia and America and the signal has to pass through the server in Thailand beforehand, so there is a delay of picture and sound. Another factor is the different speed of the Internet; in Thailand the Internet speed is lower than other countries and in this research we cannot control this factor. Therefore, reducing the delay time and developing the speed of Internet in Thailand for using the web conferencing are other points to be studied and developed in the future. In addition, the schedule of the distance consulting is not fixed enough. It is necessary to make it fixed and clear [23]. However, the result of using the distance consulting satisfies both the students and the professors because the use of this technology makes the distance consulting successful.

The students participating in this research are Ph.D. students who have done theses and research before, however, when they have to do the research at a higher level, it is more difficult because the research is more complicated and has a lot of processes. So, they need more consulting. Using the international distance consulting, it is more comfortable and flexible for the students to contact the advisor via web conferencing or mobile application that they are familiar with [24]. It is the advisors who start the consulting process by planning a schedule then preparing the consulting, preparing the tools, and making an appointment. The research team, then, study the problem from each student and once they understand the problem, the research team can provide suggestions or recommendations. The next process is to determine the quantity and deadline of the assignment for the students to modify the work and send it back to the advisor. Once the students modify the work following the framework of the research process and under the research methodologies and send it, the advisor can revise and feedback the result to the student in time. This distance consulting satisfied the students, although they do not meet the advisor directly, but their research problems can be resolved completely and they can present the thesis on the determined schedule. The distance is not a problem for the consulting, although the advisor and the advisee are in different countries. 
The graduate students who participated in the research are satisfied with the use of web conferencing as a distance consulting tool because all of them can use the system efficiently [25]. They also accept this distance learning technology, considering it as a tool for communication and learning and can use it well [26] both with the computer at home and with the web conferencing. The obstacle found in this research is the internet speed in Thailand. Most of the students use the internet of their office in the organization where the internet signal is always interrupted, the picture signal is not clear or the motion on screen is always stopped for a moment. The sound signal is also interrupted and is not continuous. This makes the users have to speak and then repeat the conversation. The students solve this problem by changing the area of work, for example at home where they have the hi-speed internet with $10 \mathrm{Mbps}$ that helps them to communicate more comfortably, particularly, when they use the mobile application 'Tango' that is a real-time videoconferencing application. For another application like 'Skype', we frequently found a problem of signal interruption, especially, when we use Skype and Facebook at the same time, because during the consulting, there are student's friends on Facebook who always interrupted the conversation by posting messages or tagging the photos of those students. The consulting, therefore, is not continuous. We suggest that the best program for an efficient consulting via web conferencing is Google's web conferencing program named 'Hang out'. The advantage of this program is that we can have a long and continuous conversation, without either disturbance of signal or any interruption during the conversation because it is a specific program.

\section{CONCLUSION}

International distance consulting via web conferencing is an economic and comfortable means of consulting in which there are not a lot of participants. It is an easy-touse tool and it has efficiency like the face-to-face real conferencing in the conference room; the difference is only that the participants are not in the same location. Although the participants are in different countries, if we consider the result of the consulting, it is not different. Thus, web conferencing is considered appropriate in this era in which the information technology plays an important role in our life style. This helps us to save expense while getting the same result.

\section{ACKNOWLEDGMENT}

The researchers would like to thanks the Central Library KMUTNB, who supports the videoconferencing; Vocational Education Technology Research Center; Science and Technology Research Institute, King Mongkut's University of Technology North Bangkok who support this research. Special thanks to the School of Computer and Security Science, Edith Cowan University, Australia, who supports the tools and location for the research.

\section{REFERENCES}

[1] European Medicines Agency. Web Conferencing Strategy, London: European Medicines Agency - an agency of the European Union, 2011.

[2] Yu, B. and Rui. Y.Web Conferencing Systems for Ubi-Media Collaboration: Achievements and Challenges. Redmond: Microsoft Research, 2010.
[3] Suduc, A-M., Bizoi, M. and Filip, F.G. Exploring Multimedia Web Conferencing. Informatica Economica vol. 13, no. 3, 2009; pp. 5-17.

[4] Seeling, P. Web Conferencing Traffic - an Analysis using DIMDIM as Example. International Journal of Computer Networks \& Communications (IJCNC). Vol.2, No.6, November 2010; pp. 1-11. http://dx.doi.org/10.5121/ijcnc.2010.2601

[5] OpenMeetings. OpenMeetings 2.0 User's manual, 2012.

[6] OpenMeetings. OpenMeetings 2.0 Administrator's manual, 2012.

[7] Greenberg, A.D. The Distance Education and e-Learning Landscape, Volume 3: Interactive Whiteboards, Web Conferencing, and Synchronous Web Tools. Duxbury, Massachusetts: Wainhouse Research, 2009.

[8] OpenMeetings. Openmeetings: Open-Source Web-Conferencing. Retrieved August 7, 2013, from http://code.google.com/ p/openmeetings/

Openmeetings: Open-Source Web-Conferencing.

Schroeder, B. Microsoft Live Meeting 2007: Web Conferencing System for Virtual Classrooms. Innovate online. Retrieved August $7, \quad 2013$, from http://www.innovateonline.info/pdf/vol1_ issue1/Rethinking_Space_and_Time_The_Role_of_Internet_Te chnology_in_a_Large_Lecture_Course.pdf

[9] Bentley, K. and Collins, S. The Evolution of Web Conferencing. Carolina: EDUCAUSE Evolving Technologies Committee.

Retrieved August 7, 2013, from http://net.educause.edu/ir/library/ pdf/DEC0705.pdf

[10] Handgraaf, M.J.J. et al. Web-conferencing as a viable method for group decision research. Judgment and Decision Making, Vol. 7, No. 5, September 2012, pp. 659-668.

[11] Cornelius, S. and Gordon, C. Learners' experiences of web conferencing: recommendations for facilitators. Aberdeen: School of Education, University of Aberdeen, 2011.

[12] Ozden, S.Y. Student Perceptions of Web-conferencing in Hybrid Classes: Action Research Project. Delaware: University of Delaware, 2010.

[13] Web Conferencing Council. Top 10 Web Conferencing Solutions 2011 Council Criteria, Findings, and Recommendations for Web Conferencing Solutions, 2011.

[14] Info-Tech Research Group (2011) Select a Web Conferencing Vendor. Retrieved August 7, 2013,from

http://www.adobe.com/content/dam/Adobe/en/products/adobecon nect/pdfs/select-webconferencing-vendor-vl-sb.pdf

[15] Web Junction group. Criteria to Consider When Selecting a Web Conferencing Provider. Retrieved August 7, 2013, from

http://www.webjunction.org/content/dam/WebJunction/Document s/webjunction/WebconfProvCriteria.pdf

[16] Oracal. (2004) Oracle Web Conferencing: Frequency-Asked Questions and Troubleshooting. Oracle September 2004. Retrieved August 7, 2013, from ttp://www.ensyncsolutions.com/library/ webconferencing_troubleshooting.pdf

[17] McCarthy, J. International design collaboration and mentoring for tertiary students through Facebook. Australasian Journal of Educational Technology. Volume 28, Issue 5, 2012, Pages 755-775. Desbrow,

[18] Irwin, C. Ball, L. B., and Leveritt, M. (2012) Students' Perceptions of using Facebook as an Interactive Learning Resource at University. Australasian Journal of Educational Technology. Volume 28, Issue 7, 2012, Pages 1221-1232.

[19] Tess, P.A. The Role of Social Media in Higher Education Classes (real and virtual) - A Literature Review. Computers in Human Behavior. Volume 29, Issue 5, 2013, Pages A60-A68. http://dx.doi.org/10.1016/j.chb.2012.12.032

[20] CISCO. Cisco Unified Meeting Place 7.0 Web Conferencing. San Jose, California: Cisco Systems, 2008.

[21] Sunkara, R.V. Oracle Web Conferencing Real-Time Collaboration System Architecture Overview. California: Oracle Corporation, 2003.

[22] Gautreau, C. et al. Video Conferencing Guidelines for Faculty and Students in Graduate Online Courses. MERLOT Journal of Online Learning and Teaching. Vol. 8, No. 4, December 2012; pp. 277287. 
[23] Pocatilu, P. et al. Mobile Learning and Mobile Technologies in Academia: A Case Study. Economic Computation and Economic Cybernetics Studies and Research. 46(3); 2012. pp. 79-98.

[24] Park, S.Y., Nam, M. and Cha, S. University students' behavioral intention to use mobile learning: Evaluating the technology acceptance model. British Journal of Educational Technology. 43(4); July 2012. pp. 592-605. http://dx.doi.org/10.1111/j.14678535.2011.01229.x

[25] Hutchison, A., Beschorner, B. and Schmidt-Crawford, D. Exploring the Use of the iPad for Literacy Learning. Reading Teacher. 66(1); September 2012, pp.15-23. http://dx.doi.org/10.1002/ TRTR.01090

\section{AUTHORS}

Prachyanun Nilsook is with the Faculty of Technical Education, King Mongkut's University of Technology North Bangkok (KMUTNB), Bangkok, Thailand, 10800 (e-mail: prachyanunn@kmutnb.ac.th).

Panita Wannapiroon is with the Faculty of Technical Education, King Mongkut's University of Technology North Bangkok (KMUTNB), Bangkok, Thailand, 10800 (e-mail: panitaw@kmutnb.ac.th).

Submitted 02 April 2014. Published as resubmitted by the authors 14 June 2014. 